\title{
LOS JÓVENES ANTE LA FE •
}

DOI: https://doi.org/10.52039/seminarios.v53i183.617

Autor: Javier Elzo Imaz. Catedrá-

Notamos que falta humus religioso tico de Sociología en la Universien el entorno de los jóvenes: no perciben para qué sirve el kerigma dad de Deusto.

El sociólogo vienés, afincado en EEUU, Peter Berger en su más que estimulante libro "Cuestiones sobre la fe" trae a colación esta formula de San Agustín: "nadie cree en algo si previamente no piensa que es creíble". Berger lo comenta señalando que hay un movimiento del credendum al credo y añade que “... este credo es el resultado de mi respuesta a una historia particular que me ha sido comunicada a través de otros seres humanos, algunos aún en vida, otros hace ya mucho desparecidos. El relato llega hasta mí como un rumor de Dios. Escucho el relato y, en el acto de fe, le respondo con un sî" 1 . Esto, exactamente esto, es lo que sucede en

- Texto de la conferencia de Javier Elzo en la Jornada de Reflexión y Encuentro "Jóvenes e Iglesia”, organizada por la Fundación Santa María, el Instituto Superior de Pastoral y PPC Ediciones en Madrid los días 27 y 28 de Octubre de 2006.

${ }^{1}$ Peter Berger, “Cuestiones sobre la fe” Ed. Herder, 2006 (paginas 30-31). 
la actualidad en muchos jóvenes, con la particularidad de que no hay humus religioso en su entorno, no perciben rumores de Dios, de modo que la fe no forma parte de lo plausible. Incluso puede suceder que el rumor que les llegue les aleje del relato de Dios. Del Dios de Jesús, quiero decir.

En efecto, y vuelvo a Peter Berger cuando más adelante (página 110) afirma, citando a Lutero, que mi fe en Cristo solamente puede tener fundamento en el reconocimiento de "Cristo para mî". La expresión "Cristo para mi" la interpreto como la necesidad de que haya un nexo capital en el kerigma del mensaje cristiano, luego también católico, en la sociedad de todos los tiempos, luego también en la sociedad actual, con las demandas, expectativas de la experiencia particular de las personas, sea individual, sea colectivamente considerada. Dicho crudamente, el kerigma cristiano, me sirve a mí o no sirve para nada. Este planteamiento, que con estas o similares palabras ya utilicé en el estudio de SM de los jóvenes españoles el año 1989, si la memoria no me falla, no debe interpretarse como si de un utilitarismo barato se tratara. Tampoco como una manifestación de una "religión a la carta". Esta afirmación significa que cuando una persona se pregunta por el sentido de la vida, de su propia vida, cuando se formula lo que vengo denominando como las primeras y últimas cuestiones de la vida (quien soy yo, si hay un más allá, si todo es inmanencia etc....) el mensaje que le llegue, le diga algo. Tan sencillo, tan elemental y tan profundo como eso. Y eso es precisamente lo que busca el joven (y cualquier persona) del kerigma religioso.

Para que se dé un nexo entre la demanda y el kerigma obviamente hay dos condiciones previas, en los extremos, y como un puente entre ambos. Por un lado es preciso que la pregunta por el sentido de la vida se formule, aún de forma implícita. El otro lado de nexo exige, no solamente que, si no la respuesta, sí al menos la pretensión de tener la respuesta exista. El nexo de unión lo conformarán, obviamente los agentes que vehiculan el anuncio con el demandante, esto es la transmisión de la fe y de forma particular el papel del agente central, la Iglesia Católica en nuestro caso.

Abordo estas cuestiones en el presente texto pero aparcando el tema de la transmisión de la fe y de los diferentes agentes de socialización, con la obligada excepción de la Iglesia como portadora del kerigma. 


\section{Aspectos de la dimensión institucional en la religiosidad de los jóvenes}

Juan González Anleo, al abordar el punto de las relaciones de los jóvenes con la iglesia en su capítulo "Jóvenes y religiosidad" del último estudio de la Fundación de 2005 refiere que "uno de los datos más estremecedores del presente Informe es la penosa imagen juvenil de la Iglesia Católica como institución, y la consiguiente negativa a concederle una confianza que, desde el punto de vista de no pocos, se merece por su dedicación a los pobres y marginados, estilo sencillo y modesto de vida, alejamiento general de intereses políticos partidistas y apertura a los problemas sociales de la sociedad española. Todo ello, pese a sus reconocidas deficiencias y tropiezos de los últimos años" Añade líneas abajo que "se ha dicho con frecuencia, hasta convertirse en un tópico bastante desgastado, que la Iglesia perdió a los intelectuales en el siglo XVIII, a la clase obrera en el XIX, y a las mujeres en el XX. En el siglo XXI está perdiendo a los jóvenes, hasta ahora la gran reserva del idealismo, de los sueños utópicos, del sano descontento con el mundo y de la promesa de cambios hacia un nuevo paradigma, idealismos y sueños que muchas veces encontraron un hogar privilegiado en la vida sacerdotal, religiosa y misionera. Los datos de este Informe no ofrecen demasiadas razones para el optimismo sobre esta pérdida eclesial. Esta pérdida se ha ido fraguando lentamente desde los años 60", concluye González Anleo. Ofrece como datos esenciales que guían la elaboración de su capítulo los que reproducimos en la tabla 1.

Tabla 1. Algunas actitudes y valoraciones de los jóvenes ante la Iglesia Católica

\begin{tabular}{|l|l|}
\hline \multicolumn{2}{|l|}{ Aspectos positivos de la Iglesia Católica } \\
\hline Creen que la Iglesia ayuda a pobres y marginados & $51 \%$ \\
\hline Creen que las normas de la Iglesia ayudan a vivir más moralmente & $35 \%$ \\
\hline Aspectos negativos de la iglesia católica & \\
\hline Creen que es demasiado anticuada en materia sexual & $82 \%$ \\
\hline No confían en la Iglesia & $80 \%$ \\
\hline Creen que la Iglesia es demasiado rica & $79 \%$ \\
No se consideran miembros de la iglesia & $70 \%$ \\
\hline Creen que se mete demasiado en política & $69 \%$ \\
\hline $\mathrm{N}=$ & 4.000 \\
\hline Fuente: Jóvenes españoles 2005 \\
\hline
\end{tabular}


Pensamos que la tabla no precisa mayores comentarios pero quizás valga la pena remontarnos a la evolución de algunos indicadores, no tanto a los años 60 pues el contexto sociopolítico era muy distinto y su análisis escapa a las posibilidades de texto pero sí, cuando sea posible, al año 1984, ya la transición política básicamente asentada y, siempre en base a los estudios de la Fundación Santa María. Es lo que ofrecemos en la tabla 2.

Tabla 2. Evolución de Indicadores juveniles (15 -24 años) acerca de la Iglesia Católica En \%

\begin{tabular}{|l|c|c|c|c|c|c|}
\hline & 1984 & 1989 & 1994 & 1999 & 2005 & $\begin{array}{c}2005- \\
\text { fecha } \\
\text { más lejana }\end{array}$ \\
\hline $\begin{array}{l}\text { Tiene mucha o bastante confian- } \\
\text { za en la Iglesia }\end{array}$ & 28 & 33 & 32 & 29 & 21 & $-7 \%$ \\
\hline $\begin{array}{l}\text { En la iglesia se dicen cosas } \\
\text { importantes en cuanto a ideas e } \\
\text { interpretaciones del mundo }\end{array}$ & - & 16 & 4 & 3 & 2 & $-14 \%$ \\
\hline $\begin{array}{l}\text { En general, estoy de acuerdo con } \\
\text { las directrices de la jerarquía de } \\
\text { la Iglesia }\end{array}$ & - & - & 36 & 28 & 17 & $-19 \%$ \\
\hline $\begin{array}{l}\text { Soy miembro de la Iglesia Cató- } \\
\text { lica y pienso continuar siéndolo }\end{array}$ & - & - & 64 & 51 & 29 & $-35 \%$ \\
\hline Soy católico practicante & 16 & 17 & 16 & 11 & 8 & $-8 \%$ \\
\hline Pertenece a asociaciones religiosas & 6 & 4 & 4 & 3,5 & 2,5 & $-3,5 \%$ \\
\hline Asiste semanalmente a misa & 17 & 17 & 15 & 11 & 4 & $-13 \%$ \\
\hline Piensa casarse por la Iglesia & 53 & 63 & 64 & 57 & 43 & $-10 \%$ \\
\hline N = & 3.343 & 4.548 & 2.028 & 3.853 & 4.000 & \\
\hline
\end{tabular}

Fuente: Estudios de la Fundación Santa María

En todos los indicadores observamos un innegable descenso, una pérdida de confianza en la Iglesia Católica, una peor valoración, una visión más crítica hacia la Iglesia Católica. Hay datos sangrantes. La absoluta irrelevancia de la Iglesia para la inmensa mayoría de los jóvenes como espacio donde se dicen cosas importantes para orientarse en la vida, el vertiginoso descenso de los jóvenes que se manifiestan miembros de la Iglesia Católica y que piensan "seguir siéndolo", que el año 2005 no llega 
al $30 \%$, menos de la mitad que diez años arriba. ¡Impresionante, ciertamente! Solamente el $17 \%$ señalan que "en general" están de acuerdo con las directrices de la jerarquía de la Iglesia. He entrecomillado "en general" pues en determinadas cuestiones el desapego es brutal. En nuestro trabajo sobre los universitarios de Deusto mostramos cómo, para el $86 \%$, la Iglesia tiene una postura anticuada sobre las libertades sexuales en general. En el conjunto de los universitarios españoles esta cifra sube al $93 \%$. Si tenemos en cuenta al porcentaje de los que no contestan a la cuestión, no llegamos al $5 \%$ de jóvenes españoles que estén de acuerdo con los planteamientos de la jerarquía católica en estos puntos. La práctica religiosa dominical es ya casi inexistente y solo se mantiene el matrimonio "por la iglesia" en un $43 \%$ de casos pero ya hay regiones en España donde el número de matrimonios no canónicos supera al de los canónicos. En fin, la confianza (mucha y bastante confianza) en la Iglesia nunca ha sido muy grande entre los jóvenes españoles pero el año 2005 apenas supera a uno de cada cinco jóvenes. Los que nos decimos católicos y ejercemos profesionalmente, como el que suscribe, en una Universidad de la Iglesia no podemos no reflexionar seriamente sobre lo que está sucediendo.

Pero no se trata solamente de actitudes ante la Iglesia Católica. Tenemos ya una importante batería de informaciones temporales socio religiosas que, en algunos casos remontan a los años 1960 y, en todo caso, desde los inicios de la transición española con la serie de estudios de la Fundación Santa María, básicamente. En mi último trabajo², paso revista a la práctica religiosa (20\% de los jóvenes decían ir a la iglesia los domingo el año 1984 y apenas son el $5 \%$ el año 2005), el 78 \% decían creer en Dios el año 1981, cifre que se reduce al $54 \%$ el año 2005. La afirmación de que "Dios existe y se ha manifestado en Jesucristo" era aceptada por el $70 \%$ de los jóvenes, muy recientemente, el año 1994, pero la cifra se queda en el 42\% el año 2005. El año 1975 el 8 \% de los jóvenes españoles (siempre estamos hablamos de jóvenes en edades comprendidas entre los $15 \mathrm{y}$ los 24 años) se decían ateos. Esta cifra sube al 21\% el año 20053. El aso-

2 Javier Elzo, "Los jóvenes y la felicidad”, Madrid 2006, Ed.PPC. páginas 221. Ver el capítulo 3, "La dimensión religiosa de los jóvenes".

3 En “Jóvenes Españoles 2005”. Pedro González Blasco (dir), Juan González- Anleo, Javier Elzo, Juan Mª . González-Anleo Sánchez, José Antonio López Ruiz, Maite Valls Iparraguirre. Fundación Santa María, Editorial S.M. 427 páginas. Madrid 2006, ver página 250, tabla 2 y comentarios de Juan González Anleo. 
ciacionismo en general cae en picado y también, aunque menos, el religioso. De hecho el $4 \%$ de los jóvenes dicen pertenecer a una asociación religiosa cuando se formula la pregunta al detalle de 14 asociaciones diferentes. No son las que salen en los medios (Legionarios de Cristo, Opus Dei, Neocatecumenales, Comunión y Liberación...) las que más adeptos tienen (no pasan del 0,2\% en nuestra encuesta) sino las parroquiales, los scouts católicos y las vinculadas a las congregaciones religiosas de siempre. En fin, la Iglesia católica que el año 1989 era citada por el $16 \%$ de los jóvenes como un espacio donde se decían cosas importantes para orientarse en la vida se queda en un escuálido 2,2\% el año 2005, una Iglesia a la que solamente el $21 \%$ de los jóvenes españoles conceden "mucha" o "bastante" confianza situándose en el punto más bajo de una larga serie de 16 instituciones puestas a la consideración de los jóvenes.

Sigo manteniendo (desde Jóvenes Españoles 99 y antes en un artículo en Sal Terrae) un diagnóstico básico, comprobable con las armas de investigación social, que resumiría en dos afirmaciones básicas:

$1^{\text {a }}$ : La gran masa de jóvenes españoles mantiene con la Iglesia una situación de divorcio asimétrico y distante

$2^{\text {a }}$ : Las distinción entre la dimensión institucional de lo religioso y la dimensión experiencia sigue siendo central y atraviesa la religiosidad juvenil española y la de gran parte de Europa occidental.

Respecto del primer punto, que lo he tratado con cierto detalle en el capítulo $3^{\circ}$ de mi libro sobre los jóvenes y la felicidad, voy a dejarlo en segundo plano, aunque al papel de otra iglesia posible volveré más adelante. Respecto del segundo punto sostenemos que hay una demanda de espiritualidad, de mística dirán otros, que manifiestamente la sociedad secular, por un lado, y las religiones históricas, en el caso español la Iglesia Católica, por el otro, tienen enormes dificultades en cubrir. Las razones o causas de este redimensionamiento son complejas y requieren tratamiento propio. Algo diremos al final de este texto. Apuntemos aquí, brevemente, que en lo que concierne a la sociedad secular parece haberse olvidado lo que ya Max Weber señalara al afirmar que lo meramente racional no agota lo humano. En efecto, hemos tardado demasiado en comprender que la secularidad está ya limitada en su propio proyecto y que estaba llamada a ser superada, una vez reconocida la limitación del conocimiento científico-técnico como único modo de aprehender la realidad, con la mentalidad asociada a este planteamiento que hacía decir que 
el modo de conocimiento religioso, e incluso el hecho mismo del fenómeno religioso, estaba abocado a la extinción en una sociedad moderna. La historia reciente está infirmando claramente este pronóstico. Añádase a ello el fracaso de la alternativa marxista, como modelo de sociedad, aun cuando mantenga vigencia en muchos aspectos su crítica al capitalismo Incluso algunas derivas fundamentalistas de lo religioso que estamos presenciando en el presente pueden leerse como consecuencias de una determinada prepotencia de la racionalidad científico-técnica del mundo occidental que ha pretendido imponer un único modelo de progreso a todo el orbe terráqueo, menospreciando la dimensión trascendente como cosa de pueblerinos, incultos y atrasados.

En Julio de 2006, merced esta vez a la huelga de pilotos de la Sepla, tuve el consabido retraso de Iberia con una demora de tres horas en Barajas. Me acerqué a un expositor de libros en el aeropuerto y anoté la lista de títulos de libros que, en la estantería de "los más vendidos", tuvieran como tema alguna cuestión religiosa o parareligiosa. Estos eran los títulos: "La Biblia de barro", "La Sombra de Dios", "La conspiración de Asís", "Los pecados de la Biblia", "El Código da Vinci", "La Rosa de David", "El Himno de los demonios", "La Cena secreta", "Al Sur de la resurrección", "El último ritual”, "A la sombra del Templo", "El Evangelio de Judas", "Caballeros de la Vera-Cruz", "Las Puertas del Paraíso", "Vaticano 2.035", "La sombra de la catedral" y "Las chicas del rosario". Diez y siete libros de temática religiosa o pseudo religiosa, en una estantería de los libros más vendidos de un aeropuerto, en una sociedad que se tiene por laica y secularizada es, como poco, algo sorprendente y llamativo. Cada día me pregunto con más fuerza si no tendremos que hablar de un entorno social pos secular y resacralizado.

Acabamos de mostrar, líneas arriba, con el recordatorio de algunos datos existentes, la evolución de los parámetros religiosos de los jóvenes, al menos en las dimensiones que podemos controlar con los métodos de la sociología que se limitan a lo que externamente podemos constatar y a lo que los propios jóvenes quieran declarar. La sociología no puede medir, por ejemplo, la fe de una persona, más allá de lo que ella quiera declarar. Hemos constatado que todos los datos parecen apuntar a un debilitamiento de la dimensión religiosa en los jóvenes. Es un diagnóstico que hemos repetido en muchas ocasiones. Pero hemos añadido también en numerosas ocasiones que la demanda religiosa, de espiritualidad, de trascenden- 
cia, de algo, cuando no de alguien, que fuera más allá de lo meramente empírico y con fecha y ámbito de caducidad terrestre, era palpable a poco que leyéramos con detalle los datos de las encuestas.

Para empezar, es preciso no olvidar que si bien el $42 \%$ de los jóvenes dicen no rezar nunca o prácticamente nunca en su vida (y la cifra va en ligero aumento), el $54 \%$ (el 4\% no contestan) sí lo hacen (rezar el padre nuestro, una oración libre y espontánea, oración de petición, meditación, oración parroquial, acción de gracias, etc). No hay que olvidar tampoco que la penetración de las sectas en España es escasa. Otra cosa será la cohabitación con otras confesiones religiosas y, en este orden de cosas, quiero saludar el enorme acierto de que haya sido una editorial católica, SM, quien haya ofrecido sus servicios a la comunidad islámica para el primer libro de texto "Descubrir el Islam". Como no hay que olvidar, en estos tiempos de sequía de vocaciones religiosas, que ya tenemos cuatro investigaciones coincidentes que nos hablan del orden de 40.000 jóvenes que en algún momento de su vida se han planteado, con seriedad, la eventualidad de la vocación religiosa. Y una quinta investigación que se publicará por la FAD en noviembre próximo, preguntados los jóvenes por las cuatro profesiones que más te gustaría desempeñar en el futuro el 0,8\% de jóvenes españoles señalan que sacerdotes, religiosos, religiosas, rabinos, imanes, etc., cifra aplicable en más del $90 \%$ de los casos a curas, religiosos o religiosas católicos, cifra que supera a los 40.000 de la estimación anterior. Por qué esta querencia no fructifica es cuestión a la que dediqué hace dos años un largo estudio y al que remito al lector interesado ${ }^{4}$.

Tampoco conviene olvidar que cuando se les pregunta a los jóvenes qué es lo que significa para ellos "ser una persona religiosa" estamos tentados de decir, y así lo hemos escrito (por ejemplo en "los Jóvenes y la felicidad", páginas 85-86), que "dan en el clavo". Ser una persona religiosa quiere decir, para los jóvenes, estar abierto a la trascendencia, creer en Dios, lo que supone mantener algún tipo de relación con esa trascendencia, mediante una práctica religiosa o mediante la oración, al par que esa religiosidad debe traducirse en una honrada apertura a los demás, ayudando a los necesitados. Amor a Dios y amor al prójimo. La mayoría de

4 “Jóvenes Españoles y Vocación” en Seminarios sobre los ministerios en la Iglesia, n $172-$ 173, Vol L. Abril-Septiembre 2004, páginas 151-400. ( $\mathrm{N}^{\circ}$ completo con una introducción de Alonso Morata). 
los jóvenes españoles están de acuerdo con esta visión de lo que supone ser religioso, de las condiciones requeribles a una persona para ser calificada como persona religiosa. Son las condiciones de la transcendencia y de la solidaridad, las que son señaladas bien por delante de las de las normas de comportamiento como "no mantener relaciones sexuales completas hasta formar una pareja para casarse" (solamente el 6\% lo señalan) o no tomar drogas (el $8 \%$ lo dicen). Una y mil veces hay que decir que para los adolescentes y jóvenes españoles la religión va por delante de la moral y de la norma. Especialmente de la norma sexual, aunque mucho menos de la norma genérica que supone decirse perteneciente a una iglesia.

Paro hay más. La demanda religiosa o, pre-religiosa, ustedes dirán- no ha desaparecido en un número muy elevado de jóvenes españoles, más bien sigue vigente, y en algunos casos con fuerza, como hemos mostrado en unas pocas tablas, que reproducimos aquí y que provienen del estudio Jóvenes y religión de SM del año de 2002 para los jóvenes españoles y del de 2003 para los universitarios de Deusto5 ${ }^{5}$. Por comodidad para el lector las traemos aquí.

Tabla 3 iTe planteas a menudo los grandes problemas (cuestiones) de la vida: el fracaso, la felicidad, el dolor, la violencia, el sentido de la vida, el mal...? (Datos en porcentajes)

\begin{tabular}{|l|c|c|c|}
\hline & Jóvenes Españoles & \multicolumn{2}{|c|}{ Universitarios } \\
\cline { 3 - 4 } & & España & Deusto \\
\hline $\begin{array}{l}\text { Son temas que me preocupan, } \\
\text { a menudo pienso en ellos }\end{array}$ & 30 & 35 & 70 \\
\hline $\begin{array}{l}\text { Algunas veces pienso en ellos, } \\
\text { pero con poca frecuencia }\end{array}$ & 45 & 46 & 25 \\
\hline $\begin{array}{l}\text { No me preocupo de esos temas, } \\
\text { nunca o casi nunca }\end{array}$ & 25 & 19 & 4 \\
\hline $\mathrm{N}=$ & 1.072 & 222 & 804 \\
\hline
\end{tabular}

Fuente: “Jóvenes 2000 y religión” y “Jóvenes de Deusto y religión”, elaboración propia.

5 González Anleo Juan (dir), González Blasco Pedro, Elzo Javier, Carmona Francisco. “Jóvenes 2000 y Religión”. Fundación Santa María. O. c. y en J. Elzo, M ${ }^{\mathrm{a}}$ T. Laespada y T.L. Vicente. “Jóvenes de Deusto y religión”. O. c. 
Tabla 4. ¿Con quién compartes esas inquietudes? (Respuestas múltiples. En porcentajes)

\begin{tabular}{|l|c|c|c|}
\hline & Jóvenes Españoles & \multicolumn{2}{|c|}{ Universitarios } \\
\cline { 3 - 4 } & & España & Deusto \\
\hline Con tus amigos & 70 & 77 & 71 \\
\hline Con tus padres/tu familia & 36 & 43 & 50 \\
\hline Con tu pareja (si la tienes) & 29 & 27 & 38 \\
\hline Con algún sacerdote o religioso/a & 4 & 7 & 6 \\
\hline Con algún profesor & 2 & 2 & 2 \\
\hline No lo compartes con nadie & 15 & 16 & 15 \\
\hline N = (solo los que se plantean esas cuestiones) & 803 & 180 & 764 \\
\hline
\end{tabular}

Fuente: “Jóvenes 2000 y religión” y “Jóvenes de Deusto y religión”, elaboración propia.

Tabla 5. ¿Qué importancia tiene la religión para ti, en tu vida personal? (En porcentajes)

\begin{tabular}{|l|c|c|c|}
\hline & Jóvenes Españoles & \multicolumn{2}{|c|}{ Universitarios } \\
\cline { 3 - 4 } & & España & Deusto \\
\hline Mucha & & 10 & 10 \\
\hline Bastante & 24 & 22 & 25 \\
\hline Poca & 40 & 43 & 38 \\
\hline Ninguna & 26 & 23 & 25 \\
\hline $\mathrm{N}=$ & 1.072 & 222 & 804 \\
\hline
\end{tabular}

Fuente: “Jóvenes 2000 y religión” y “Jóvenes de Deusto y religión”, elaboración propia.

Los datos son extremadamente interesantes. Además del $10 \%$ de jóvenes que manifiestan "mucho" interés y otro $25 \%$ "bastante" por la religión "en su vida personal”, las cifras muestran que hay cifras importantes de jóvenes a quienes les importan las grandes cuestiones de la vida, el fracaso, la felicidad, el dolor, la violencia, el sentido de la vida, el mal etc. Son algunas de las grandes cuestiones previas y concomitantes con las religiones a lo largo y ancho de la historia y del mundo entero. Esas preguntas, esas inquietudes no han desaparecido, en absoluto, en la juventud 
actual. Además en proporciones altamente significativas. El $30 \%$ de los jóvenes españoles en edades comprendidas entre los 13 y los 24 años afirman plantearse "a menudo" esas cuestiones, el $45 \%$ se lo plantean "a veces" y solamente uno de cada cuatro jóvenes se dicen completamente ajenos a estas cuestiones. Cifras importantes, cifras que, como era lógicamente esperable, son superiores entre los universitarios. Es miopía ideológica seguir sosteniendo que las cuestiones religiosas son cosa de gente sin formación. Otra cosa es decir que las respuestas que se den a esas cuestiones serán, evidentemente, atendidas con mayor aparato crítico por quienes su formación se lo permita y que la respuesta no se va a decantar, necesariamente, por la fe religiosa.

Los datos de Deusto, muy llamativos y que analizamos en el estudio correspondiente y al que remitimos al lector interesado, los explicamos, al menos parcialmente, por lo que venimos denominando como el propio efecto Deusto. Aquí nos limitamos a resaltar un hecho. Una vez dentro de la universidad, la demanda de presencia cristiana por parte de los alumnos supera incluso el posible rechazo a un exceso de presencia de tal suerte que si algo habría que cambiar en la Universidad de Deusto, estiman los alumnos, que habría de hacerse en el sentido de una mayor presencia o visibilidad de la dimensión cristiana. Este dato muestra que aunque la secularización ha sido brutal y rápida en la sociedad vasca la demanda religiosa, y explícitamente cristiana en la Universidad de Deusto, no ha desparecido en absoluto. A más abundamiento hay que añadir que entre los alumnos de fin de carrera esta demanda se hace aún más patente al par que disminuye el porcentaje de los que la estiman excesiva6. La conclusión se impone: entre los universitarios de Deusto a más formación, más demanda religiosa.

Pero, a continuación hay que leer con suma atención los resultados que nos ofrece la tabla 4 pues nos va a dar una de las claves para entender la desafección institucional de lo religioso, de la búsqueda de "una religión a la carta" y hasta de la inconsistencia cognoscitiva de muchos de los planteamientos religiosos juveniles. Nos interrogamos con quien comentan nuestros jóvenes sus inquietudes sobre el sentido de la vida, sobre el

\footnotetext{
6 Javier Elzo, M ${ }^{\mathrm{a}}$ Teresa Laespada y Trinidad L. Vicente. “Jóvenes de Deusto y religión”. Cuadernos de Teología Deusto, no 32. Ed. Facultad de Teología. Universidad de Deusto 2004. Bilbao. 119 páginas, ver p. 41 y ss.
} 
fracaso, la felicidad, el dolor, la violencia, el mal, etc. La respuesta que nos dan los propios jóvenes es sumamente importante. Estas cuestiones las comentan, en primer y destacado lugar, con los amigos, con la familia en segundo lugar, con su pareja, los que la tienen, en tercer lugar (pero si el porcentaje lo hiciéramos solamente sobre los que tienen pareja subiría al primero o segundo lugar, dejando atrás a los padres) y, en el furgón de cola, encontramos a los sacerdotes o religiosos y, en menor proporción aún, a los profesores. Este dato es clave y muestra, a la evidencia, que, incluso en temas de este calado, los amigos y la pareja (cuando la tienen) ocupan el primer lugar de socialización, de referencia, de persona donde encontrar ayuda, insisto que para los temas centrales de la vida, no simplemente para comentar sus cosas de todas los días, las clases para los estudiantes, el trabajo para lo que están ya en ese mundo, las chicas para los chicos y los chicos para ellas etc.

Hemos dicho más arriba que este ámbito de inquietudes se corresponde como el previo o el concomitante con el ámbito religioso. Otros hablan de cuestiones pre-religiosas. Sea lo que sea, lo cierto es que cuando nos interrogamos sobre los agentes de socialización juvenil en general y después profundizamos en los agentes de socialización pertinentemente religiosa llegamos a las mismas conclusiones: la Iglesia como Institución apenas tiene predicamento como agente de socialización y los padres ( $\sin$ más precisiones sobre su fe religiosa) dejan de tenerlo cuando pasamos de las cuestiones más genéricas a las de la socialización religiosa. De nuevo los amigos, y la pareja cuando existe, se llevan la palma.

\section{La oferta religiosa}

El otro lado del nexo exige, ya lo hemos dicho más arriba que haya propuestas de respuesta a la demanda religiosa pero propuestas de respuesta que tengan plausibilidad social y cultural para los sujetos que las demandan. Nadie pondrá en duda que esas propuestas de respuesta existen. En nuestro contexto estamos hablando de la religión católica, evidentemente. Juan Pablo II en el extraordinario encuentro con los jóvenes en Tor Vergara, cerca de Roma, lo dijo con claridad y rotundidad meridiana dirigiéndose a los dos millones de jóvenes que tenía delante: "es Jesucristo el que vosotros buscáis cuando soñáis en la felicidad”. 
Sin embargo a nadie que consulte con ojos limpios los datos científicos se le puede escapar que hay un hiato entre la demanda religiosa y la aceptación del kerigma católico en la juventud de España, aún con todas las precisiones, niveles y distinciones que se quieran hacer según las regiones, edades, sexo (cada día más imprevisible) y, sobre todo, "iter" personal y familiar de cada joven. Estamos ante un dato sociológico incontestable que hace que la fe religiosa encuentre grandes dificultades para manifestarse en la juventud de hoy, en la España de hoy.

En varios sitios he ofrecido un avance de explicación sociológica de este hiato, enunciando una serie de aspectos que, a nuestro juicio, deben ser tenidos en cuenta a la hora de entender las actitudes y valoraciones que mantienen los jóvenes españoles hacia la Iglesia católica. Son reflexiones que llevamos haciendo estos últimos años y que actualizamos continuamente 7 . Para este texto nos centramos solamente en aquellas cuestiones eclesiales que tienen mayor proximidad con las cuestiones de fe.

Tres apuntes de entrada:

$1^{\circ}$. En el actual contexto de globalización nos parece central abordar la distinción entre el principio de verdad absoluta con pretensiones de universalidad y el relativismo del "toda opinión vale", imposibilitando, de hecho, un planteamiento holístico intelectualmente riguroso. Es preciso distinguir el "relativismo" del todo vale de la "relatividad" frente a la pretensión de verdad única universalizable a todo el género humano. Es preciso superar la polaridad entre, por un lado, el imperio de lo efímero, fragmentario, lo meramente subjetivo y, por el otro, la pretensión de ser los únicos detentores de la única verdad. Esta cuestión es particularmente importante en el tema de la verdad religiosa. No todas las religiones valen, pero tampoco podemos pretender que solo la fe católica es la única verdadera y es la única mediación de salvación. Esta cuestión, por mil razones, es crucial.

$2^{\circ}$. El proceso de individualización como primer corolario del proceso de secularización del que estamos saliendo con dos ámbitos diferenciados:

- La dimensión occidental: aunque la dimensión religiosa, como tal, tiene un espacio cada día más importante, incluso en los estudios de ciencia sociológica, la plausibilidad del mensaje eclesial es cada día menor, estamos pasando de la religiosidad institucionalizada a la

${ }^{7}$ La última vez en nuestro libro "Los jóvenes y la felicidad”, o.c. ver capítulo 3, apartado 11. 
religiosidad experiencial. De ahí la desacralización que señalábamos arriba.

- En España no acabamos de salir de la memoria histórica del nacional-catolicismo: especialmente en los adultos y en los medios de comunicación social, cada día más ideológicamente sesgados hacia los partidos políticos que defienden. ¿Volvemos a las dos Españas?

$3^{\circ}$. Es del todo punto pertinente la reflexión de Cerezo y Gómez en su reciente trabajo sobre Jóvenes e Iglesia cuando escriben que "la postmodernidad abre la puerta a un nuevo estatuto de la racionalidad: junto a la razón científica, teórica, especulativa, tiene cabida la razón estética, emocional, simbólica. Se introduce así, en un nivel racional, lo mítico-religioso, los sentimientos, la experiencia religiosa...que son considerados como una dimensión de la razón. Pero implica también un saber débil acerca de Dios desde el punto de vista racional. Se puede decir que es una "fe no creída", sino más bien "sentida" 8 . Ciertamente ahí estamos. Yo haría dos prolongaciones a la reflexión de los autores.

No estoy seguro que el saber de Dios de generaciones anteriores fuera más fuerte por más razonado. Sería probablemente más sólido por ser socialmente menos cuestionado. Tras el estudio de Jóvenes españoles 2005, creo que la polarización religiosa entre los jóvenes españoles no se daría entre creyentes y no creyentes, sin más, sino entre creyentes practicantes (católicos practicantes más correctamente en nuestro contexto) agnósticos y algunos ateos, por un lado, quedando en una magma relativa pero no totalmente indiferenciada todavía que, según la clasificación que se lleva operando desde hace más de cuarenta años en las encuestas de opinión, conformaría a los católicos poco o nada practicantes, a los indiferentes, y a los ateos sociológicos, por el otro. Si hace 20 y más años todavía era correcto hablar de católicos sociológicos, en el sentido de que su catolicidad respondía al "humus" dominante en la sociedad española, hoy, con el mismo criterio, cabe hablar de no creyentes sociológicos agrupando ahí, "sensu estricto" a gran parte de los ateos a los indiferentes y, "sensu lato" ciertamente a los católicos nada practicantes.

\footnotetext{
8 José Joaquín Cerezo y Pedro José Gómez Serrano: “Jóvenes e Iglesia. Caminos para el reencuentro”. Fundación Santa María, Editorial PPC, Madrid 2006, páginas 53-54.
} 
La segunda nota se refiere a la fe sentida más que creída. Este tema es clave y es una de las notas mayores de la sociedad actual. En ese contexto yo introduciría un tercer elemento: el concepto de credulidad. Piénsese en la lista de libros esotéricos arriba mencionados. Me pregunto si más allá del secularismo lo que hay es un descentramiento de las creencias religiosas, a veces incluso una ocultación del núcleo de la fe cristiana por la espuma de lo secundario. Me refiero a la búsqueda de escapatorias a la asfixia de la inmanencia, especialmente en personas que no disponen, sea de convicciones asentadas (en la creencia o en la increencia), sea de recursos dialecticos para la soledad de la duda.

Centrándonos en España, estos últimos tiempos, tras el fallecimiento de Juan Pablo II y la elección de Benedicto XVI he escrito en varios medios sobre lo que los jóvenes retendrán de Juan Pablo II y lo que esperan del nuevo papa. En Vida Nueva lo resumí con un título muy expresivo: un líder religioso ${ }^{9}$. En el fondo es lo que esperan de la Iglesia, bien que personalizada en su primera figura, el Papa, máxime en un tiempo de incertidumbres, ayuno de líderes. Retomo algunas ideas pero trasladadas al conjunto eclesial.

En una sociedad en la que parece que solo cuenta el dinero y el poder, la apariencia, el espectáculo que deslumbra con sus luces ocultando la sed de autenticidad y verdad, una sociedad que no sabe distinguir secularismo de secularidad, laicismo de laicidad, los jóvenes recordarán de Juan Pablo II, se lo pedirán a Benedicto XVI y a toda la Iglesia, que proclame con fuerza que la vida tiene un sentido, que hay que afrontar las cuestiones centrales de la vida: quién soy yo, por qué estoy aquí, por qué he de hacer el bien y no el mal, por qué el otro es mi hermano y no mi enemigo; una Iglesia que les abra a la trascendencia, que el mundo no se acaba aquí; que hay un alfa y un omega; una Iglesia que sea compasiva, humana, (jamás, jamás entenderán una Iglesia inhumana, y todavía hoy, a veces lo es), una Iglesia que muestre, como acaba de hacerlo, aún titubeante, Benedicto XVI en su Encíclica "Deus caritas est" que Dios es amor, un amor que tiene su traslado en la vida interpersonal, un amor que no se agota en el "eros" y que tiene su culmen en el "agape", un amor que debe marcar el ser y estar en la sociedad de la Iglesia católica. También una Iglesia que proclame que la persona no es solo sujeto de derechos sino también de

\footnotetext{
9 Javier Elzo “Un líder religioso a quien poder seguir”. En Vida Nueva, Especial Nuevo Pontificado, 23 Abril 2005, nº 2.468, páginas 14-15.
} 
deberes. Sí, una Iglesia que defiende los derechos humanos, que se opone a guerra, como se opuso Juan Pablo II a la guerra del Golfo, a la de Irak.

Personalmente creo que los jóvenes, los que han experimentado la presencia de Juan Pablo II, sea físicamente, sea a través de los medios, no retendrán de sus discursos lo que decía sobre la sexualidad, ni lo que decía sobre el aborto, la eutanasia, la manipulación genética, sus opiniones sobre la homosexualidad etc., etc. Es el Papa religioso el que retendrán los jóvenes de Juan Pablo II y eso será lo que busquen en su sucesor. Un Papa que les hable de Dios, del Dios que se ha manifestado, entre nosotros, en Jesucristo, un Dios único que ha tenido también otras manifestaciones históricas. Un Papa que, como Juan Pablo II rezó en Asís, abrazó al rabino de Roma, visitó su Sinagoga, un Papa que rece también en una Mezquita y de un paso más en el largo y complicado camino, aunque imprescindible a mi juicio, hacia el reconocimiento, en las diferentes Iglesias y Confesiones religiosas, del pluralismo religioso. Benedicto XVI, en referencia al próximo encuentro en Asís, previsto par los días 4 al 7 de noviembre próximos ha tenido un recuerdo especial para los jóvenes con estas palabras: “...los orantes de las diferentes religiones pudieron mostrar (en el encuentro de Asís de 1986), con el lenguaje del testimonio, que la oración no divide sino que une, y que constituye un elemento determinante para una eficaz pedagogía de la paz, basada en la amistad, en la acogida recíproca, en el diálogo entre los hombres de diferentes culturas y religiones. Tenemos más necesidad que nunca, especialmente si prestamos atención a las nuevas generaciones. Muchos jóvenes, en las zonas del mundo caracterizadas por conflictos, son educados en sentimientos de odio y venganza, en contextos ideológicos en los que se cultivan las semillas de antiguos rencores y se preparan los espíritus para futuras violencias. Es necesario abatir estas empalizadas y favorecer el encuentro. Me alegro por el hecho de que las iniciativas programadas en este año en Asís vayan en esta dirección y porque el Consejo Pontificio para el Diálogo Interreligioso haya pensando en su aplicación particularmente a los jóvenes"10.

Juan Pablo II ha situado la pregunta religiosa en el centro de esta sociedad europea, para asombro e incredulidad de tantos para quienes Dios y la religión no son sino manifestación de una sociedad retrógrada y que

\footnotetext{
10 Del "Mensaje del Papa con motivo del 20 aniversario Encuentro Interreligioso por la Paz en Asís" (Zenit 4 de Septiembre de 2006).
} 
pensaban ver desaparecer con la alta modernidad. Benedicto XVI en su primera encíclica ha remachado con fuerza donde esta la esencia del Dios de los católicos: en el amor como entrega.

Digámoslo una y mil veces. Los jóvenes que miran, a sus modos y maneras, a la Iglesia le piden que ponga el acento en la dimensión religiosa más que en el cumplimiento de normas que, en gran medida, no entienden y rara vez ven cumplir en los mayores. Una Iglesia que muestre a Dios, al Dios que se ha manifestado, entre nosotros, en Jesucristo, un Dios entendible más allá de la concepción mítica de la salvación según el esquema "paraíso-caída-castigo-redención-gloria", que deje paso a la secuencia "creación (desde el amor)-crecimiento histórico-culminación en Cristo-gloria" que tan lúcida y gráficamente ha mostrado Torres Queiruga ${ }^{11}$, un Dios que, aunque único, ha tenido también otras manifestaciones históricas. Una Iglesia que avance, sin prepotencias ni temores, hacia el diálogo con otras confesiones religiosas en la aceptación sincera del pluralismo religioso, omnipresente en una sociedad globalizada. Una Iglesia que, al fin, invite a las mujeres a participar y ejercer en la Iglesia en el mismo rango que los hombres. Una Iglesia que no mire con recelo a la ciencia, tanto de las llamadas puras como sociales, que no tenga miedo de los hombres de ciencia que buscan honradamente el bienestar de las gentes, el progreso y, a la postre, la felicidad. Una Iglesia que rompa con la tradición eclesial de aceptar la evolución de las cosas siempre con años, cuando no siglos, de retraso. Una Iglesia que participe, sin miedo de nuevo, de la conversación de las gentes del mundo, mostrando la luz del Evangelio. Me duele profundamente que la Iglesia esté, todavía en la actualidad, continuamente mirando los avances de la ciencia con miedo y que buena parte de la historia de la Iglesia haya sido, de entrada, una negación continua a todo lo que de novedoso haya propuesta la ciencia y el arte. Creo que hay que hacer realidad lo que dijo Benedicto XVI en la televisión alemana sobre que el catolicismo no es un cúmulo de prohibiciones. Ya va siendo hora de que la Iglesia no aparezca como el reino del 'no', sino como el reino de la presentación positiva de las cosas ${ }^{12}$. Lo cual no quiere decir que no tenga que decir 'no' en ocasiones.

11 . A. Torres Queiruga, en "La imagen de Dios tras la ruptura de la modernidad", en el colectivo "Hay lugar para Dios hoy” en Editorial PPC, Madrid 2005, paginas 54-56.

12. Quizás sea interesante transcribir en su integridad la pregunta formulada al papa y su repuesta completa - Pregunta RV: Tema: la familia. Hace un mes usted estuvo en Valencia para 
Sí, también una Iglesia que también sepa decir "No" cuando haya que decir "No". Una Iglesia que ante el dinero como mera acumulación de riquezas, anteponga la solidaridad, ante el poder como agente de influencia de los "míos", anteponga el poder como servicio, ante el sexo seguro como solo placer sitúe, en un plano superior, el amor, sin trabas, con el ser querido con quien se quiere construir un proyecto de vida compartido. Los jóvenes le entenderán y, muchos, le seguirán. En definitiva una Iglesia que los jóvenes la vean próxima, una Iglesia de su mundo y de su tiempo.

\section{Por un nuevo paradigma en la Iglesia española}

Pero todo esto, centrándonos en la iglesia española, exige un nuevo

celebrar el Encuentro Mundial de las Familias. Quien ha escuchado con atención - como hemos intentado hacerlo desde «Radio Vaticano» - se ha dado cuenta de que usted no ha pronunciado la palabra «matrimonio homosexual», no ha hablado de aborto, ni de contraconcepción. Atentos observadores se han dicho: ¡Interesante!, evidentemente su intención es anunciar la fe y no dar la vuelta al mundo como «apóstol de la moral». ¿Nos puede hacer un comentario al respecto?

- Benedicto XVI: Claro que sí. Ante todo tengo que decir que tuve solamente dos ocasiones de veinte minutos para hablar. Teniendo tan poco tiempo no se puede comenzar diciendo: «no». Tenemos que saber qué es lo que queremos decir, ¿no es así? Y el cristianismo, el catolicismo no es un cúmulo de prohibiciones, sino una opción positiva. Y es muy importante que esto se vea nuevamente, ya que hoy esta conciencia ha desaparecido casi completamente. Hemos oído hablar tanto de lo que no está permitido que ahora hay que decir: tenemos una idea positiva que proponer; el hombre y la mujer están hechos el uno para el otro; existe, por así decir, una escala - sexualidad, éros, ágape - , que indica las dimensiones del amor y sobre este camino crece desde siempre el matrimonio, como encuentro entre un hombre y una mujer, cúlmen de la felicidad y de la bendición, y después la familia, que garantiza la continuidad entre generaciones, en la que las generaciones se reconcilian entre ellas y en la que también las culturas se pueden encontrar. Por lo tanto, ante todo es importante subrayar lo que queremos. En segundo lugar, se puede ver después también el porqué nosotros no queramos algo. Y yo creo que sea necesario ver y reflexionar, ya que no se trata de una invención católica el hecho de que un hombre y una mujer estén hechos el uno para el otro para que la humanidad continúe a vivir: lo saben todas las culturas. En relación al aborto, no pertenece al sexto, sino al quinto mandamiento: «No matarás». Y esto tenemos que presuponerlo como obvio y tenemos que rebatir siempre que la persona humana inicia en el seno materno y sigue siendo persona humana hasta el último aliento. El hombre tiene que ser respetado siempre como hombre. Pero todo esto queda más claro, si antes hemos explicado lo positivo. (Zenit 16 de Agosto de 2006). 
hora de proyectar su "estar en la sociedad española". Incluso esta realidad es poco dependiente del color político del gobierno de turno. Por ejemplo la espinosa cuestión de la financiación de la Iglesia católica vía el IRPF, quedó inconclusa tras ocho años de gobierno del PP, aunque recientemente parece haberse llegado a un acuerdo. La cuestión de la clase de religión no se resolvió más que al final de esos ocho años y la decisión adoptada es hoy cuestionada sin que todavía se haya llegado a una solución satisfactoria.

Nos parece excesivo el peso de las relaciones institucionales que mantiene la Iglesia Institución y el Estado, especialmente cuando estas relaciones se llevan a cabo al amparo de los Acuerdos con la Santa Sede. Digámoslo claramente: esos Acuerdos son ya un anacronismo y, lo que es peor, desde una perspectiva de evangelización, un obstáculo mayor al papel de la Iglesia en una sociedad que ya no es una sociedad de cristiandad. Lo decimos con las palabras que utiliza Claude Dagens, Obispo de Angulema refiriéndose, obviamente, a la Iglesia de Francia: "Emerge hoy una situación relativamente nueva para la religión cristiana en nuestras democracias occidentales. Hemos salido o estamos saliendo del sistema de relaciones institucionales de fuerza que han dominado durante mucho tiempo las relaciones entre la Iglesia y el Estado. Traduzcamos esto para Francia: la Iglesia Católica ya no tiene una posición hegemónica. La Iglesia ya no pretende cuadricular la sociedad, pero no se resigna a la privatización de la fe. Desea que la propuesta cristiana, el Evangelio de Cristo, contribuya a la vida de nuestra sociedad....El desafío ante el que nos encontramos es relativamente nuevo: se trata de inscribir nuestra experiencia cristiana en el interior del tejido social, deseando que esta voluntad pueda ser reconocida, no en razón de un poder institucional, sino a partir de nuestra fe vivida y libremente propuesta"13.

Este planteamiento, no excluye las relaciones institucionales entre la Iglesia y el Estado pero las sitúa, con todas las salvedades y peculiaridades que se quieran, en las que existen en el seno de una sociedad moderna entre sociedades y entidades que agrupan a diferentes personas y el Estado, en el marco de la autonomía de las realidades terrestres, por seguir la terminología de "Gaudium et Spes" del Concilio Vaticano II, como una

\footnotetext{
13 Claude Dagens, "La nouvauté chrétienne dans la société française. Espoirs et combats d'un évêque".
} 
realidad aceptada por la Iglesia institución. Parece claro que el Estado democrático (que no se pretenda militantemente ateo, o que sostenga el carácter exclusivamente privado de lo religioso, lo que no sé que es peor) no puede no reconocer, respetar y procurar satisfacer, por ejemplo, la voluntad de millones de sus ciudadanos que quieren una determinada educación para sus hijos. Pero esa negociación debe hacerse, no en virtud de anacrónicos acuerdos interestatales sino como respuesta de un Estado, que se pretenda democrático, a las exigencias de sus ciudadanos creyentes agrupados, en este caso de forma mayoritaria, en la Iglesia Católica. Lo que no supone que no deba atender a las demandas de las personas de otras confesiones religiosas. También si son inmigrantes, obviamente.

Lo que, a su vez, reenvía la cuestión a los miembros de la propia Iglesia, no sola ni principalmente a sus Obispos, si nos centramos, de nuevo, en la Iglesia Católica. En última instancia será la vitalidad de la Iglesia, de los miembros de la Iglesia, inteligentemente encuadrados -pero esta es otra cuestión, apenas abordada- la que determine no solamente las relaciones de la iglesia con el estado sino, mucho más profundamente, la presencia de la iglesia, como seguidores en la fe en Jesucristo, en la sociedad. Puestas así las cosas, será el dinamismo de la fe de los cristianos y su visibilidad social lo que hará más presente su mensaje en la sociedad. Los católicos no conforman un colectivo apartado de la sociedad, retirado de la sociedad (salvo carismas particulares, minoritarios y bienvenidos) sino miembros, como los demás, de la misma sociedad, partícipes como ellos del momento histórico que les ha tocado vivir que, en el momento actual, un momento de mutación ante un pasado que se nos aleja sin que nos sirva de referente, un futuro del que apenas nada podemos prever, más allá de los próximos meses, generando como consecuencia lógica un presente azaroso en el que la tentación de encerrarse en su mundo próximo y seguro, "entre los suyos" es una tentación permanente. Es en esta incertidumbre social que el católico español debe vivir su fe.

Vivir su fe, anunciar a Jesús el Resucitado, es la causa y razón última de su autoafirmación como cristiano, como católico adulto. Ciertamente se es católico, en primer lugar, porque se ha nacido en un lugar concreto y en una familia concreta. Pero un cristianismo y una fe adultos exigen posicionarse en una sociedad que se ha emancipado, en una sociedad que se ha hecho autónoma, en una sociedad que ha adoptado la autonomía de las realidades terrenas. De ahí que la cuestión sociológica se convierta en 
cuestión teológica. De qué estamos hablamos cuando decimos que tenemos fe, de qué Dios hablamos cuando decimos que creemos en Dios, de qué salvación hablamos, cuando decimos que Jesús vino al mundo para salvarnos, en qué consiste el Reino de Dios, etc. Cuestiones de una acuidad central en una sociedad que ha asumido su autonomía aunque eso no suponga, en absoluto, que haya vuelto la espalda a la transcendencia. La sociedad actual no ha evacuado a Dios de sus vidas. Simplemente se pregunta quién es Dios en quién decimos los creyentes que creemos. Y un cristiano adulto, contemporáneo con la sociedad del siglo XXI en la que vive y sin estériles y esterilizantes añoranzas de otros tiempos, debe dar cuenta, con la razón y el compromiso, de lo que dice que cree.

\section{De la importancia del kerigma}

Llegados a este punto la pregunta que se impone es la de saber qué lectura católica del anuncio de Jesús tenga más verosimilitud, más plausibilidad en el mundo juvenil actual. No se trata de acomodaciones o atajos. Menos aún de rebajas. Sino del núcleo central de la fe para el joven de hoy. Junto a ello hay que preguntarse qué perfil de joven cabe asociar a unos u otros "conocimientos de Cristo", cuestión esta que nadie parece atreverse a formular, menos aún a indagar, y qué consecuencia tiene todo esto en la presencia de las vocaciones religiosas (y qué vocaciones) y, más importante todavía, en la capacidad de levadura en la sociedad concreta actual. Cuando el Papa Juan Pablo II señalaba que "el deseo de ser sacerdote se alimenta esencialmente de la intimidad con el Señor, en un diálogo verdaderamente personal, que se expresa ante todo como el deseo de estar con Él" es imposible no estar de acuerdo, como imposible es no preguntarse de qué Señor estamos hablando. Aquí estamos, en mi modesta opinión, en el punto neurálgico. Todo pasa por la concepción del Dios que se ha manifestado en Jesús Encarnado y Resucitado que se sostenga, en y para los jóvenes de hoy, no para los jóvenes atemporales, lo que se corresponde con la concepción de Dios que se sostiene, ofrece y presenta a la sociedad, a la sociedad real y concreta de hoy.

Esto nos lleva directamente al tema del anuncio de la fe, a la predicación global de la buena nueva realizada por Cristo, nos interroga sobre el kerigma como acontecimiento único en la historia, como invitación a la fe, el kerigma como el choque de la buena nueva que tiene que impresio- 
nar a los hombres del mundo entero, el kerigma que da sentido a una vida, el kerigma como acicate y esbozo de respuesta a las primeras y últimas preguntas de la vida, el kerigma como anunciador de dónde está esa felicidad que se persigue a lo largo de la vida. Es la cuestión del kerigma anterior a la catequesis, el kerigma real en la tradición católica de hoy para los hombres y mujeres de hoy, para los jóvenes de hoy. La pregunta es si el kerigma actual permite que Jesús sea reconocido e identificado como el Cristo, Señor, salvador universal, centro de la historia, que invite a los jóvenes a la conversión y a la fe. Entenderán que repita para terminar que estamos ante una cuestión que, al final, es más teológica que sociológica. Y aquí el sociólogo debe ya callar. 